\title{
Individualized Folic Acid Supplementation based on Polymorphisms of Methylenetetrahydrofolate Reductase (MTHFR) and Methionine Synthase Reductase (MTRR), Compared with Traditional Folic Acid Supplementation, Reduces Gestational Diabetes Mellitus
}

\author{
Xiaoying Yu \\ Shaoxing Second Hospital \\ Le Diao \\ Shanghai Zhangjiang Institute of Medical Innovation, Shanghai Biotecan Pharmaceuticals Co., Ltd \\ Baoying Du \\ Shaoxing Second Hospital \\ Ying Wang \\ Shaoxing Second Hospital \\ Xiaoqin Xv \\ Shaoxing Second Hospital \\ Anqi Yu \\ Shanghai Zhangjiang Institute of Medical Innovation, Shanghai Biotecan Pharmaceuticals Co., Ltd \\ Jiangman Zhao ( $\nabla$ zhaojiangman86@163.com) \\ Shanghai Zhangjiang Institute of Medical Innovation, Shanghai Biotecan Pharmaceuticals Co., Ltd
}

\section{Research Article}

Keywords: Folic acid, Gestational diabetes mellitus, Polymorphisms, Pregnancy

Posted Date: January 3rd, 2022

DOI: https://doi.org/10.21203/rs.3.rs-1168960/v1

License: (9) (i) This work is licensed under a Creative Commons Attribution 4.0 International License. Read Full License 


\section{Abstract}

Backgroud: Folic Acid (FA) may contribute to the development of gestational diabetes mellitus (GDM), but existing studies are inconsistent. We examined the genotype distributions and allele frequencies of methylenetetrahydrofolate reductase (MTHFR) C677T, A1298C and methionine synthase reductase (MTRR) A66G polymorphisms of pregnant women in China, and compared the effects of individualized folate supplementation and traditional FA supplementation on GDM.

Methods: The genotype distributions and allele frequencies of MTHFR C677T, A1298C and MTRR A66G polymorphisms in 968 pregnant women (case group) were tested. FA metabolism was ranked at four levels, and then pregnant women of different levels are supplemented with different doses of FA at different periods. The case group was followed up for pregnancy complications and compared with 1,940 pregnant women traditionally supplemented with FA in the same hospital (control group).

Results: The allele frequencies of MTHFR C677T were 63.3\% (C) and 36.7\% (T), those of MTHFR A1298C were 79.3\% (A) and $20.7 \%(C)$, and those of MTRR A66G were $75.0 \%(A)$ and $25.0 \%(G)$. Compared with control group, the incidence of GDM in the case group were significantly lower, especially in high-risk pregnant women after FA supplementation.

Conclusion: Traditional FA supplementation based on personal habits is controversial, but the use of polymorphisms of genes to clarify the FA metabolism of pregnant women, appropriate, timely and accurate supplementation of FA can effectively reduce gestational diabetes, especially for high-risk pregnant women.

\section{Introduction}

Folic acid (FA) is a synthetic form of folate necessary for cell development and biochemical reactions [1]. It is worth noting that a low intake of FA can also increase the risk of adverse pregnancy outcome [2,3]. Lack of FA in pregnant women will increase the risk of birth defects, especially neural tube malformations [4]. At the same time, the incidence of other birth defects will increase, such as Down's syndrome, cleft lip and palate, and congenital heart disease. FA supplementation for pregnant women can reduce the prevalence of fetal neural tube defects which often leading to death or disability [5]. Some studies demonstrated that FA supplementation continued throughout pregnancy prevents adverse pregnancy outcomes, whereas some study suggest that high-dose FA may lead to an increased risk of gestational hypertension [1, 6]. In addition, high doses of FA continued throughout pregnancy are not an effective prevention strategy for preeclampsia [7]. Excessive FA supplementation can increase the risk of breast cancer in pregnant women, lead to zinc deficiency in the body and cause abnormal fetal development and cover up vitamin B12 deficiency. Research stated that attention should be given to avoid inappropriate FA supplement use in women who are planning or capable of pregnancy $[1,6]$. FA effects may be more relevant in subjects carrying genetic abnormalities of the enzymes of homocysteine metabolic pathway, in particular, the common homozygous thermolabile 5,10 methylentetrahydrofolate reductase (MTHFR C677T) [1]. This indicates that, according to polymorphisms of MTHFR and other related genes, it is very important to guide pregnant women to accurately supplement FA.

Gestational diabetes mellitus (GDM) is diagnosed when a woman has high blood sugar levels for the first time during pregnancy [8] and the prevalence of GDM is more than 20\% in Asian [9]. Higher habitual intakes of supplemental folate before pregnancy were significantly associated with lower GDM risk [10]. But recently research have been conducted that daily intake of FA during early pregnancy was associated with a higher risk of GDM in China [11]. Addition, higher maternal folate coupled with vitamin B12 insufficiency was associated with higher GDM risk in Singapore [12]. However, none of these studies provide accurate FA supplementation for pregnant women based on Polymorphisms of genes.

A number of studies have investigated variations in genes related to folate metabolism $[13,14]$. Several key enzymes, including methylenetetrahydrofolate reductase (MTHFR), methionine synthase (MTR), and methionine synthase reductase (MTRR) are involved in the folate metabolic pathway [15]. MTHFR is involved in the one-carbon cycle, and is a crucial enzyme that regulates nucleotide synthesis and DNA methylation [14, 16]. The MTHFR C677T gene polymorphism (rs1801133) and A1298C gene polymorphism (rs1801131) are common gene variants of MTHFR and have been shown to alter the enzyme activity [14, 16]. Methionine as a precursor for S-adenosylmethionine, is produced via the transfer of a methyl group from 5-

Page 2/11 
methyltetrahydrofolate, which is catalyzed by MTR and MTRR $[17,18]$. Similar to MTHFR C677T and A1298C, MTRR A66G is also a common polymorphism, which plays an important role in folate metabolism [14].

Recently research revealed that after supplemented with FA, the complication rates were significantly reduced, especially for GDM, compared with pregnant women without FA supplementation [14]. However, there are limited studies on the relationship between FA supplementation and the risk of gestational diabetes in the Chinese population. There has been consensus on the necessity and benefits of FA supplementation for pregnant women. However, few studies have used polymorphisms of gene to accurately guide pregnant women to supplement FA during pregnancy. Most studies are based on experience or common sense in life. In particular, it is crucial to identify high-risk pregnant women through genetic testing methods, more accurate FA supplementation and more careful care. Therefore, we compared the difference between pregnant women with empirical FA supplementation and pregnant women with genetic guidance and precise FA supplementation during pregnancy to identify high-risk pregnant women and highlight the necessity and importance of genetic testing to accurately guide pregnant women to supplement FA.

\section{Materials And Methods}

\section{Study population and SNP genotyping}

The study was approved by the ethics committee of Shaoxing Second Hospital. A total of 2908 pregnant women were enrolled in this study between 2014 and 2019. Clinical information including age, body mass index (BMI), history of abortion, first pregnancy, physical activities, and diseases of reproductive system during pregnancy was completed by all subjects. Informed consent was obtained from all participants. The study protocol conformed to the ethical guidelines of the 1975 Declaration of Helsinki and was approved by the Medical Ethics Committee of Shaoxing Second Hospital. Informed consent was obtained from all participants. SNP of MTHFR C677T, MTHFR A1298C and MTRR A66G were determined by PCR and Sanger sequencing by $\mathrm{ABI} 3730 \mathrm{XL}$ DNA Analyzer (ABI, USA).

\section{Assessment of Potential Risk and Individualized Intervention with FA}

A total of 968 cases of individualized intervention of FA through genetic testing polymorphisms and 1,940 cases of controls with empirical supplementation of FA were included in this study.

According to the genotypes of these three polymorphisms, the FA metabolism ability of pregnant women was evaluated. The risk of abnormal pregnancy outcome was further evaluated and divided into four levels: unidentify, low, middle and high, and then supplemented with different doses of FA according to the risk level of abnormal pregnancy outcome and its gestational age.

\section{Assessment of GDM}

GDM was diagnosed at the same clinic visit, based on plasma glucose concentrations measured at a fasting state and two hours after a $75 \mathrm{~g}$ oral glucose tolerance test (OGTT) was administered. Plasma glucose concentrations were analyzed using the colorimetry method (Advia 2400 Chemistry system, Siemens Medical Solutions Diagnostics; and Beckman LX20 Pro analyzer, Beckman Coulter). Participants were classified as having GDM, if they met one of the following: (1) $\geq 4.5 \mathrm{mmol} / \mathrm{L} \mathrm{of}$ fasting plasma glucose concentrations, (2) $\geq 10 \mathrm{mmol} / \mathrm{L}$ and $8.5 \mathrm{mmol} / \mathrm{L}$ of plasma glucose concentrations 1-hour and 2-hour post-OGTT, respectively.

\section{Complications Observation and Statistical Analysis}


The complications of pregnant women in cases and controls, including GDM, thyroid function, gestational hypertension, abortion, premature birth, macrosomia and underweight were recorded and analyzed. Statistical analysis were performed using SPSS 19.0 (IBM, NY, USA). If continuous variables conformed to a normal distribution, unpaired t-tests were used to analyze differences. Otherwise, the Mann-Whitney $U$ test was used. When comparing datasets containing multiple groups, one-way analysis of variance was used for normally distributed datasets, and the Kruskal-Wallis test was used for datasets not normally distributed. Categorical variables were summarized as the counts and percentages, and analyzed using the c2 test or Fisher's exact test, as appropriate. A two-sided values of $\mathrm{P}<0.05$ were considered statistically significant.

\section{Results}

\section{Participant characteristics}

History of abortion, first pregnancy, diseases of reproductive system, Body Mass Index (BMI) and age according to maternal characteristics are presented in Table 1. Case pregnant women tended to be younger, which is significant lower than control pregnant women (median 28 vs. $30, P<0.001$ ). The proportion of case pregnant women with reproductive system diseases is higher than that of control pregnant women (percentage, $5.27 \%$ vs. $1.49 \%, \mathrm{P}<0.001$ ). There were no significant differences in $\mathrm{BMI}$, history of abortion, and first pregnancy between the two groups.

Table 1

Clinical characteristics of case and control pregnant women.

\begin{tabular}{|llll|}
\hline Clinical characteristics & Cases & Controls & P value \\
\hline Age / years & $28(16-44)$ & $30(17-47)$ & $<0.001$ \\
Median (range) & & & \\
\hline BMI / Mean \pm SD & $21.75 \pm 2.98$ & $21.69 \pm 3.11$ & 0.289 \\
\hline History of abortion & $458(47.31 \%)$ & $867(44.69 \%)$ & 0.181 \\
\hline First pregnancy & $333(34.40 \%)$ & $692(35.67 \%)$ & 0.500 \\
\hline Diseases of reproductive system & $51(5.27 \%)$ & $29(1.49 \%)$ & $<0.001$ \\
\hline
\end{tabular}

\section{Distribution of Genotypes and Allelic Frequencies Relative to Polymorphisms of the MTHFR and MTRR Genes}

The distribution of genotype and allele frequencies of polymorphisms in the case group are presented in Table 2. The distribution of genotype of MTHFR C677T were 39.8\% (CC), 47.0\% (CT) and 13.2\% (TT); those of MTHFR A1298C were 63.4\% (AA), 31.7\% (AC) and 4.9\% (CC), and those of MTRR A66G were $55.6 \%(A A), 38.7 \%(A G)$ and $5.7 \%(G G)$. The allele frequencies of MTHFR C677T were $63.3 \%(C)$ and $36.7 \%(T)$; those of MTHFR A1298C were $79.3 \%(A)$ and $20.7 \%(C)$, and those of MTRR A66G were $75.0 \%(A)$ and $25.0 \%(G)$. 
Table 2

Distribution of genotype and allele frequencies of polymorphisms

\begin{tabular}{|lllll|}
\hline & Genotypes & Frequency & Allele & Frequency \\
\hline MTHFR C677T & CC & $385(39.8 \%)$ & C & $63.3 \%$ \\
\hline & CT & $455(47.0 \%)$ & T & $36.7 \%$ \\
\hline MTHFR A1298C & AT & $128(13.2 \%)$ & & \\
\hline & AC & $614(63.4 \%)$ & A & $79.3 \%$ \\
\hline MTRR A66G & AC & $47(307(31.7 \%)$ & C & $20.7 \%$ \\
\hline & AA & $538(55.6 \%)$ & A & $75.0 \%$ \\
\hline & AG & $375(38.7 \%)$ & G & $25.0 \%$ \\
\hline & GG & $55(5.7 \%)$ & & \\
\hline
\end{tabular}

\section{FA metabolic capacity and supplement}

FA metabolism is further ranked according to the genotypes of pregnant women, including four levels: unidentify, low, middle and high. According to the genotype and gestational weeks in Table 3, guide pregnant women to supplement individualized FA dosage. 
Table 3

Risk rank of folate metabolism and FA supplementation

\begin{tabular}{|c|c|c|c|c|}
\hline \multirow[t]{2}{*}{ Risk rank } & \multirow{2}{*}{$\begin{array}{l}\text { Genotypes } \\
\text { (MTHFR C677T/ MTHFR A1298C/ } \\
\text { MTRR A66G) }\end{array}$} & \multicolumn{3}{|c|}{ Folic acid supplementation } \\
\hline & & $\begin{array}{l}3 \text { months before } \\
\text { conception }\end{array}$ & $\begin{array}{l}\text { Early pregnancy (0- } \\
12 \text { weeks) }\end{array}$ & $\begin{array}{l}\text { Late pregnancy (13- } \\
40 \text { weeks) }\end{array}$ \\
\hline \multirow[t]{2}{*}{ Unidentify } & CC AA AA & $400 \mu \mathrm{g} /$ day & $400 \mu \mathrm{g} /$ day & dietary \\
\hline & CC AC AA & & & \\
\hline \multirow[t]{2}{*}{ Low } & CT AA AA & $400 \mu \mathrm{g} /$ day & $400 \mu \mathrm{g} /$ day & $400 \mu \mathrm{g} /$ day \\
\hline & CT AC AA & & & \\
\hline \multirow[t]{12}{*}{ Middle } & CC CC AA & $400 \mu \mathrm{g} / \mathrm{day}$ & $800 \mu \mathrm{g} /$ day & $400 \mu \mathrm{g} /$ day \\
\hline & CC AA AG & & & \\
\hline & CC AC AG & & & \\
\hline & CC AA GG & & & \\
\hline & CC AC GG & & & \\
\hline & CT CC AA & & & \\
\hline & CT AA AG & & & \\
\hline & CT AC AG & & & \\
\hline & CT AA GG & & & \\
\hline & CT AC GG & & & \\
\hline & TT AA AA & & & \\
\hline & TT AC AA & & & \\
\hline \multirow[t]{11}{*}{ High } & CC CC AG & $800 \mu \mathrm{g} /$ day & $800 \mu \mathrm{g} /$ day & $400 \mu \mathrm{g} /$ day \\
\hline & CC CC GG & & & \\
\hline & CT CC AG & & & \\
\hline & CT CC GG & & & \\
\hline & TT CC AA & & & \\
\hline & TT AA AG & & & \\
\hline & TT AC AG & & & \\
\hline & TT AA GG & & & \\
\hline & TT AC GG & & & \\
\hline & TT CC AG & & & \\
\hline & TT CC GG & & & \\
\hline
\end{tabular}

Frequency complications after supplementation with FA during Pregnancy in the case and control pregnant women

The frequency complications after supplementation with FA during Pregnancy in the case and control pregnant women are presented in Table 4. We found that GDM was significantly reduced in the case group, compared with those in control groups $(P<0.001)$. The macrosomia was also reduced in the case group, compared with those in control groups $(P<0.031)$. The 
complications of thyroid function, gestational hypertension, abortion, premature birth and underweight were not significantly different between these two groups.

Table 4

Frequency complications after supplementation with FA during pregnancy in the case and control pregnant women.

\begin{tabular}{|llll|}
\hline Clinical characteristics & $\begin{array}{l}\text { Cases } \\
(\mathrm{N}=968)\end{array}$ & $\begin{array}{l}\text { Controls } \\
(\mathrm{N}=1940)\end{array}$ & P value \\
\hline Gestational diabetes mellitus & $55(5.7 \%)$ & $220(11.3 \%)$ & $<0.001$ \\
\hline Thyroid function & & & \\
\hline Hypothyroidism & $15(1.6 \%)$ & $19(1.3 \%)$ & 0.545 \\
\hline Hyperthyreosis & $122(13.0 \%)$ & $182(12.5 \%)$ & 0.691 \\
\hline Normal & 800 & 1259 & \\
\hline Missing & 31 & 480 & \\
\hline Gestational hypertension & $12(1.2 \%)$ & $28(1.4 \%)$ & 0.657 \\
\hline Premature birth & 43 & 91 & 0.359 \\
\hline Macrosomia (>4kg) & $40(4.4 \%)$ & $131(6.5 \%)$ & 0.031 \\
\hline Underweight (<2.5kg) & $8(0.9 \%)$ & $16(0.8 \%)$ & 0.879 \\
\hline Apgar score (<8) & $15(1.7 \%)$ & $35(1.8 \%)$ & 0.736 \\
\hline
\end{tabular}

\section{Risk rank of folate metabolism, distribution, and corresponding gestational complications frequency}

The corresponding gestational complications of GDM, hypothyroidism, hyperthyreosis and gestational hypertension under risk rank of folate metabolism were summarized in Table 5. In case group, the percent of pregant women at four risk including unidentify, low, middle and high, is $18.4 \%, 27.0 \%, 46.9 \%$ and $7.7 \%$, respectively. Compared with unidentify, low and middle levels in pregnant women, the GDM among the high risk levels in pregnant women were obviously reduce (percent $18.4 \%, 27.0 \%$, $46.9 \%$ vs. $7.7 \%$ ). There were no significant differences among the four risk levels for hypothyroidism, hyperthyreosis and gestational hypertension in pregnant women. 
Table 5

Risk rank of folate metabolism, distribution, and corresponding gestational complications frequency, according to genotypes.

\begin{tabular}{|c|c|c|c|c|c|c|c|c|}
\hline Risk rank & $\begin{array}{l}\text { MTHFR } \\
\text { C677T }\end{array}$ & $\begin{array}{l}\text { MTHFR } \\
\text { A1298C }\end{array}$ & $\begin{array}{l}\text { MTRR } \\
\text { A66G }\end{array}$ & $\begin{array}{l}\begin{array}{l}\mathbf{N} \\
\text { (percent) }\end{array} \\
\mathrm{N}=968\end{array}$ & $\begin{array}{l}\text { Gestational } \\
\text { diabetes } \\
\text { mellitus }\end{array}$ & $\begin{array}{l}\text { Gestational } \\
\text { hypertension }\end{array}$ & Hypothyroidism & Hyperthyreosis \\
\hline \multirow[t]{2}{*}{ Unidentify } & $\mathrm{CC}$ & AA & AA & $\begin{array}{l}178 \\
(18.4 \%)\end{array}$ & $12(6.7 \%)$ & $2(2.1 \%)$ & $5 / 175$ (2.9\%) & $\begin{array}{l}19 / 175 \\
(10.9 \%)\end{array}$ \\
\hline & $\mathrm{CC}$ & $A C$ & AA & & & & & \\
\hline \multirow[t]{2}{*}{ Low } & CT & AA & AA & $\begin{array}{l}261 \\
(27.0 \%)\end{array}$ & $14(5.4 \%)$ & $3(1.6 \%)$ & $1 / 252(0.4 \%)$ & $\begin{array}{l}28 / 252 \\
(11.1 \%)\end{array}$ \\
\hline & CT & $\mathrm{AC}$ & AA & & & & & \\
\hline \multirow[t]{11}{*}{ Middle } & TT & AA & AA & $\begin{array}{l}454 \\
(46.9 \%)\end{array}$ & $28(6.2 \%)$ & $6(1.3 \%)$ & $7 / 439$ (1.6\%) & $\begin{array}{l}62 / 439 \\
(13.7 \%)\end{array}$ \\
\hline & $\mathrm{CC}$ & AA & $A G$ & & & & & \\
\hline & $\mathrm{CC}$ & $A C$ & $A G$ & & & & & \\
\hline & $\mathrm{CC}$ & AA & GG & & & & & \\
\hline & $\mathrm{CC}$ & $A C$ & GG & & & & & \\
\hline & $\mathrm{CC}$ & $\mathrm{CC}$ & AA & & & & & \\
\hline & CT & $\mathrm{CC}$ & AA & & & & & \\
\hline & CT & AA & $A G$ & & & & & \\
\hline & CT & $A C$ & $A G$ & & & & & \\
\hline & $\mathrm{CT}$ & AA & GG & & & & & \\
\hline & CT & $A C$ & GG & & & & & \\
\hline \multirow[t]{5}{*}{ High } & TT & $\mathrm{AA}$ & $A G$ & $\begin{array}{l}75 \\
(7.7 \%)\end{array}$ & $1(1.3 \%)$ & $1(1.9 \%)$ & $2 / 72(2.8 \%)$ & $13 / 72(17.3 \%)$ \\
\hline & TT & $A C$ & $A G$ & & & & & \\
\hline & $\mathrm{CC}$ & $\mathrm{CC}$ & $A G$ & & & & & \\
\hline & TT & AA & GG & & & & & \\
\hline & $\mathrm{CC}$ & $\mathrm{CC}$ & GG & & & & & \\
\hline
\end{tabular}

Note: Thyroid function is missing in 29 cases.

\section{Discussion}

The folate metabolism pathway plays an important role in cell division $[3,19]$ and DNA methylation, repair and synthesis [2022], and it is critically important for the health of pregnant women and the development of fetuses [14]. Research showed that FA supplementation continued throughout pregnancy prevents adverse pregnancy outcomes [1]. MTHFR is a key enzyme in folate metabolism [23]. Some genetic polymorphisms code for a less efficient enzyme, increasing serum concentrations of homocysteine [23]. This has been associated with inadequate feto-maternal circulation and increased risk of adverse pregnancy outcome [14, 23]. Two polymorphic variants in this gene (C677T and A1298C) have been implicated in a mild form of MTHFR deficiency associated with hyperhomocysteinemia [24]. Recently studies have showed that the C677T and A1298C Single-nucleotide polymorphisms (SNPs) of the MTHFR gene could elevate blood homocysteine [25-27], which may cause 
fetal nervous system malformation and spina bifida cystica [28]. The MTRR mutation prevents the conversion of homocysteine to methionine and is the main cause of FA and methyl vitamin deficiency. Among them, A66G is the most important and most studied mutation and has the risk of elevating blood homocysteine [29]. Through the polymorphisms of MTHFR C677T, A1298C and MTRR A66G, it is possible to detect the level of FA absorption and utilization by different individuals as soon as possible, thereby screening high-risk groups prone to FA deficiency, and realizing personalized FA supplements to reduce the risk of pregnancy syndrome and birth defects in newborns.

The rate of GDM in the case group is significantly lower than the control group. Especially in high-risk pregnant women, there are fewer pregnant women with GDM. In the case group, there are 75 of pregnant women at high risk, but only a pregnant women have GDM, which is the lower among pregnant women with other three risk levels. FA has a significant effect on GDM [14]. A higher intake of habitual FA supplementation before pregnancy is significantly associated with a lower risk of GDM [10]. FA can increase the nitric oxide (NO) level and restore Type II diabetes associated-endothelial dysfunction [30]. In addition, we also noticed that pregnant women in the control group were older than those in the case group, but there were significantly more pregnant women in the case group with reproductive system diseases than the control group. Age may be a possible risk factor for pregnancy complications [14]. This indicates that for older pregnant women with reproductive system diseases, accurate FA supplementation through gene polymorphism testing may be more important.

In this research, the pregnant women at high risk, that is pregnant women with poor FA metabolism, the precise FA supplement dose significantly reduces the risk of gestational diabetes. Therefore, compared with pregnant women who have not supplemented with FA [14] or supplemented with FA according to common sense, it is clinically beneficial to identify high-risk pregnant women and individualized supplementation of FA according to polymorphisms of genes. As a consequence, the results show that, compared with traditional FA supplementation, individualized FA supplementation based on the polymorphisms of MTHFR and MTRR may be a powerful measure to reduce GDM.

\section{Conclusions}

According to Polymorphisms of genes, pregnant women who accurately supplemented FA had a lower risk of diabetes during pregnancy than non-tested pregnant women, and this event was more pronounced in high-risk pregnant women. Too much or too little FA supplement according to personal habits is controversial, and the use of genetic testing to clarify the FA metabolism of pregnant women, appropriate and timely and accurate supplementation of FA can effectively reduce gestational diabetes, especially for high-risk pregnant women.

\section{Declarations}

\section{AUTHOR CONTRIBUTIONS:}

JMZ, XYY and LD conceived and designed the study. XYY, BYD, YW, XQX and AQY acquired the data. JMZ and XYY analyzed and interpreted the data. LD and XYY drafted the article.

\section{ACKNOWLEDGEMENTS:}

None.

\section{CONFLICTS OF INTEREST:}

All authors report no conflict of interest related to the submitted work.

\section{FUNDING:}


This research did not receive any specific grant from funding agencies in the public, commercial, or not-for-profit sectors.

\section{Ethics approval and consent to participate}

This study was approved by the Ethics Committee of Shaoxing Second Hospital, Shaoxing, China. All participants signed an informed consent. All methods were carried out in accordance with relevant guidelines and regulations.

\section{Consent for publication}

Not applicable.

\section{Competing interests}

The authors declare that they have no competing interests.

\section{References}

1. Orabona R, Zanardini C, Zatti S, Sartori E, Prefumo F. Folic Acid Supplementation in Pregnancy: A Matter of Doses? Hypertension. 2020;76:30-1.

2. Kontic-Vucinic O, Sulovic N, Radunovic N. Micronutrients in women's reproductive health: I. Vitamins. Int J Fertil Womens Med. 2006;51:106-15.

3. Scholl TO, Johnson WG. Folic acid: influence on the outcome of pregnancy. Am J Clin Nutr. 2000;71:1295S-303S.

4. Czeizel AE. Periconceptional folic acid and multivitamin supplementation for the prevention of neural tube defects and other congenital abnormalities. Birth Defects Res A Clin Mol Teratol. 2009;85:260-8.

5. Force USPST, Bibbins-Domingo K, Grossman DC, Curry SJ, Davidson KW, Epling JW, Jr., et al. Folic Acid Supplementation for the Prevention of Neural Tube Defects: US Preventive Services Task Force Recommendation Statement. JAMA. 2017;317:183-9.

6. Li Q, Xu S, Chen X, Zhang X, Li X, Lin L, et al. Folic Acid Supplement Use and Increased Risk of Gestational Hypertension. Hypertension. 2020;76:150-6.

7. Wen SW, White RR, Rybak N, Gaudet LM, Robson S, Hague W, et al. Effect of high dose folic acid supplementation in pregnancy on pre-eclampsia (FACT): double blind, phase III, randomised controlled, international, multicentre trial. BMJ. 2018;362:k3478.

8. American Diabetes A. Diagnosis and classification of diabetes mellitus. Diabetes Care. 2011;34 Suppl 1:S62-9.

9. Guariguata L, Linnenkamp U, Beagley J, Whiting DR, Cho NH. Global estimates of the prevalence of hyperglycaemia in pregnancy. Diabetes Res Clin Pract. 2014;103:176-85.

10. Li M, Li S, Chavarro JE, Gaskins AJ, Ley SH, Hinkle SN, et al. Prepregnancy Habitual Intakes of Total, Supplemental, and Food Folate and Risk of Gestational Diabetes Mellitus: A Prospective Cohort Study. Diabetes Care. 2019;42:1034-41.

11. Zhu B, Ge X, Huang K, Mao L, Yan S, Xu Y, et al. Folic Acid Supplement Intake in Early Pregnancy Increases Risk of Gestational Diabetes Mellitus: Evidence From a Prospective Cohort Study. Diabetes Care. 2016;39:e36-7.

12. Lai JS, Pang WW, Cai S, Lee YS, Chan JKY, Shek LPC, et al. High folate and low vitamin B12 status during pregnancy is associated with gestational diabetes mellitus. Clin Nutr. 2018;37:940-7.

13. Colson NJ, Naug HL, Nikbakht E, Zhang P, McCormack J. The impact of MTHFR $677 \mathrm{C} / \mathrm{T}$ genotypes on folate status markers: a meta-analysis of folic acid intervention studies. Eur J Nutr. 2017;56:247-60.

14. Li X, Jiang J, Xu M, Xu M, Yang Y, Lu W, et al. Individualized supplementation of folic acid according to polymorphisms of methylenetetrahydrofolate reductase (MTHFR), methionine synthase reductase (MTRR) reduced pregnant complications. 
Gynecol Obstet Invest. 2015;79:107-12.

15. Weiner AS, Boyarskikh UA, Voronina EN, Tupikin AE, Korolkova OV, Morozov IV, et al. Polymorphisms in folate-metabolizing genes and risk of idiopathic male infertility: a study on a Russian population and a meta-analysis. Fertil Steril. 2014;101:87-94 e3.

16. Zhou TB, Drummen GP, Jiang ZP, Li HY. Methylenetetrahydrofolate reductase (MTHFR) C677T gene polymorphism and diabetic nephropathy susceptibility in patients with type 2 diabetes mellitus. Ren Fail. 2015;37:1247-59.

17. Ren ZJ, Zhang YP, Ren PW, Yang B, Deng S, Peng ZF, et al. Contribution of MTR A2756G polymorphism and MTRR A66G polymorphism to the risk of idiopathic male infertility. Medicine (Baltimore). 2019;98:e18273.

18. Xu L, Qin Z, Wang F, Si S, Li L, Lin P, et al. Methylenetetrahydrofolate reductase C677T polymorphism and colorectal cancer susceptibility: a meta-analysis. Biosci Rep. 2017;37.

19. Scott JM, Weir DG, Molloy A, McPartlin J, Daly L, Kirke P. Folic acid metabolism and mechanisms of neural tube defects. Ciba Found Symp. 1994;181:180-7; discussion 7-91.

20. Karimian M, Hosseinzadeh Colagar A. Methionine synthase A2756G transition might be a risk factor for male infertility: Evidences from seven case-control studies. Mol Cell Endocrinol. 2016;425:1-10.

21. Luo WP, Li B, Lin FY, Yan B, Du YF, Mo XF, et al. Joint effects of folate intake and one-carbon-metabolizing genetic polymorphisms on breast cancer risk: a case-control study in China. Sci Rep. 2016;6:29555.

22. Mc Auley MT, Mooney KM, Salcedo-Sora JE. Computational modelling folate metabolism and DNA methylation: implications for understanding health and ageing. Brief Bioinform. 2018;19:303-17.

23. Blanco-Munoz J, Lacasana M, Gamboa R, Huesca-Gomez C, Hernandez-Mariano JA, Aguilar-Garduno C. Interaction between MTHFR 677C>T, PON1 192Q >R and PON1 55L >M polymorphisms and its effect on non-recurrent spontaneous abortion in Mexican women. Gene. 2019;689:69-75.

24. Levin BL, Varga E. MTHFR: Addressing Genetic Counseling Dilemmas Using Evidence-Based Literature. J Genet Couns. 2016;25:901-11.

25. Jacques PF, Bostom AG, Williams RR, Ellison RC, Eckfeldt JH, Rosenberg IH, et al. Relation between folate status, a common mutation in methylenetetrahydrofolate reductase, and plasma homocysteine concentrations. Circulation. 1996;93:7-9.

26. Motulsky AG. Nutritional ecogenetics: homocysteine-related arteriosclerotic vascular disease, neural tube defects, and folic acid. Am J Hum Genet. 1996;58:17-20.

27. Chedraui P, Salazar-Pousada D, Villao A, Escobar GS, Ramirez C, Hidalgo L, et al. Polymorphisms of the methylenetetrahydrofolate reductase gene (C677T and A1298C) in nulliparous women complicated with preeclampsia. Gynecol Endocrinol. 2014;30:392-6.

28. Mills JL, Scott JM, Kirke PN, McPartlin JM, Conley MR, Weir DG, et al. Homocysteine and neural tube defects. J Nutr. 1996;126:756S-60S.

29. Ranganathan P, McLeod HL. Methotrexate pharmacogenetics: the first step toward individualized therapy in rheumatoid arthritis. Arthritis Rheum. 2006;54:1366-77.

30. van Etten RW, de Koning EJ, Verhaar MC, Gaillard CA, Rabelink TJ. Impaired NO-dependent vasodilation in patients with Type II (non-insulin-dependent) diabetes mellitus is restored by acute administration of folate. Diabetologia.

2002;45:1004-10. 